\title{
Medical and graduate students' attitudes toward personal genomics
}

\author{
Kelly E. Ormond, $M S^{1,2}$, Louanne Hudgins, MD', Jennifer M. Ladd ${ }^{2}$, David M. Magnus, PhD ${ }^{2,3}$, \\ Henry T. Greely, $J D^{1,2,4}$, and Mildred K. Cho, $P h D^{2,3}$
}

\begin{abstract}
Purpose: Medical schools are being approached by direct-to-consumer genotyping companies about genotyping faculty or trainees as a method to "teach" them about the potential implications of genotyping. In thinking about the future incorporation of genotyping into a graduate level genetics course, the purpose of this study was 2-fold: first, to assess knowledge, attitudes, and beliefs of students toward personal genomics as it related to themselves as both as customers and future physicians and as it related to consumers at large, and second, to determine the impact of the course (as taught without genotyping) on knowledge, attitudes, and beliefs. Methods: We surveyed first-year medical students and graduate students before and after a core genetics course. Results: After the course, students were less likely to believe that genotyping information would be useful to physicians, patients, or consumers; genotyping would provide information to improve their own personal health; or personal genomic testing services are diagnostic of medical conditions. They were more likely to answer knowledge questions accurately after the course but still had difficulty with clinical interpretation. Despite these changes, a slight majority of students were, and remained, interested in undergoing genotyping themselves. Of note, the number who believed genotyping "would help them understand genetic concepts better than someone else's data" decreased. General curiosity was the most commonly chosen reason for interest in undergoing genotyping, and approximately $50 \%$ of respondents expressed concern about confidentiality of results. Conclusions: In conclusion, even without the genotyping process, an educational program about genotyping increased knowledge, particularly about the clinical limitations of genotyping, but student interest in genotyping did not significantly change. Institutions thinking about offering genotyping to their students as part of a learning experience should consider the pros and cons of doing so. Genet Med 2011:13(5):400-408.
\end{abstract}

Key Words: personalized genotyping, personalized genomic testing, direct-to-consumer testing, genetic education

"Pentin ersonal genome" testing (PGT) services that are commercially available as direct-to-consumer (DTC) tests from a number of sources such as Navigenics, 23\&Me, or deCODEme, promise to revolutionize health care. For the purposes of this study, we define PGT as whole-genome analysis that is directly available to consumers for the purpose of identifying health-

From the ${ }^{1}$ Department of Genetics; ${ }^{2}$ Stanford Center for Biomedical Ethics; ${ }^{3}$ Department of Pediatrics, Division of Medical Genetics; and ${ }^{4}$ Stanford Law School, Stanford University, Stanford, California.

Kelly Ormond, MS, 300 Pasteur Drive M/C 5208, Stanford, CA 94305-5208. E-mail: kormond@stanford.edu.

Disclosure: Kelly E. Ormond served as a paid consultant for Navigenics from July 2007 to July 2009, before the onset of this study. The remaining authors declare no conflict of interest.

Submitted for publication July 27, 2010.

Accepted for publication November 5, 2010.

Published online ahead of print January 25, 2011.

DOI: 10.1097/GIM.0b013e31820562f6 related genes or genotypes. At this point, such services are primarily based on single nucleotide polymorphism (SNP) genotyping. Indeed, TIME magazine named the Retail DNA Test as its 2008 Invention of the Year. ${ }^{1}$ Community hospitals (such as El Camino Hospital in Mountain View, CA) are also beginning to incorporate genetic testing and genome-wide analysis into health care as the core of personalized medicine programs. Others, such as the Coriell Institute for Medical Research are testing the utility of personal genomics in large research-based populations.

However, in the face of this expansion, there are concerns that genetic testing is not adequately regulated to ensure a minimum level of safety and efficacy, ${ }^{2-6}$ the results of such tests could provide little improvement to health but drive up costs of health care, ${ }^{7,8}$ and advertising and information provided about DTC tests are inaccurate. 9,10 There is also concern about the genetic literacy of clinicians ${ }^{11-13}$ and how they will communicate information about personalized genomics to their patients. Physicians in all specialties and genetics professionals will be at the forefront of caring for and counseling users of PGT services. In addition, they are likely to be at the leading edge as consumers, potentially being early adopters of genetic and associated informatics technology. ${ }^{14}$ Even if PGT services do not require the involvement of clinicians, the companies providing the services encourage discussing results with health care providers, and limited data suggest that potential consumers who reported being interested in obtaining PGT services would likely consult a physician about the results. ${ }^{15}$ Therefore, because they could be asked to provide counseling and follow-up clinical services as a result of consumers acquiring PGT, it is important to understand what clinicians and trainees know and think about such services.

Because of the potential future importance of personal genomics in medicine and translational research, faculty at Stanford University School of Medicine considered plans to incorporate genotyping of students into genetics courses to enhance the learning process. These plans proposed to offer genotyping services to students, who would receive their individual test results confidentially so that others would not know who obtained their genotypes or what the results were, but some proposals included group analysis of data in class sessions and others included the manipulation of personal genome data in classroom learning exercises. These proposals engendered debate on campus about whether such genotyping should be conducted, and if so how, with the discussion centered on issues of privacy and confidentiality of results, potential for coercion, conflicts of interest and perception of institutional endorsement of commercial services, need for counseling and medical follow-up of genetic results, and potential for psychosocial and other harms.

These discussions eventually resulted in one such course being offered, but before that happened, we conducted an anonymous survey of medical and graduate students enrolled in the introductory human genetics course at Stanford University School of Medicine to evaluate the students' attitudes toward and knowledge about PGT. Although it was not the primary 
purpose of the course, we asked respondents to think about PGT services as it related to them as both as customers and future physicians and as it related to consumers at large. We also evaluated the effect of the course on attitudes and knowledge by administering the survey before and after the course.

\section{MATERIALS AND METHODS}

\section{Participants}

The study population comprised students enrolled in a human genetics course (GENE 202) at Stanford University School of Medicine. First-year medical students are required to enroll in this core course or to take another upper-level genetics course that is more research-oriented. Approximately 76 first-year medical students and 10 other students (primarily undergraduates planning to enter medicine or an allied health field, students completing a masters degree in a biological science, or medical residents/fellows, typically in obstetrics or maternal fetal medicine) were enrolled in GENE 202 during Fall Quarter 2009. Participation in this study was anonymous and voluntary and was not in any way linked to their completion of, or grade in, the course, and the survey links were sent to all students in the class on two separate occasions. Forty-three participants completed the first survey ( $48 \%$ response rate) and 31 participants completed the second survey (36\% response rate). To maintain anonymity, the two surveys were not linked, and we did not collect demographic information on respondents. However, aggregate demographic information on the first-year medical student class $(N=86)$ is as follows: mean age, 24 years (range, 21-34 years); 53\% female; and 19\% from underrepresented minority groups (defined as African American, Latino, Native American, Native Hawaiian, and Southeast Asian). To further maintain anonymity, no information was collected about computer Internet Protocol addresses. Secure Sockets Layer technology was used to maintain confidentiality of results.

\section{Course curriculum}

The human genetics course was directed by two of the authors (K.O. and L.H.). It came after a 22-hour Molecular Medicine course required of all medical students (but not taken by the other students enrolled in GENE 202). The earlier course had spent 4 hours introducing students to basic concepts in molecular biology including SNPs and to PGT using the example of a course director's personal testing results. The human genetics course encompassed 32 hours of instruction and covered topics of clinical importance in human genetics and genetic counseling. Approximately 8 hours of the course were devoted to genotyping and whole genome sequencing, with lectures (primarily given by K.O. and other university faculty) that included an overview of genomewide association studies and whole genome sequencing technologies. Faculty used specific examples in their teachings (such as broadly reviewing diabetes studies and their clinical validity and utility) and compared information available from several DTC testing companies and nonprofit projects, but they did not present specific scenarios similar to the questions asked in the clinical scenarios portion of the survey. Other authors provided additional ethics instruction on confidentiality (D.M.) and facilitated a mandatory discussion on the social and ethical applications of such information (K.O. and H.G.).

\section{Survey}

The survey was constructed to assess respondents' beliefs, attitudes, and knowledge about personal genomics. The same survey, containing identical questions in the same order, was completed at the beginning of the course and 8 weeks later at the end of all instruction.

On the basis of the questionnaire developed by McGuire et al., ${ }^{15}$ we created a survey that included 43 Likert-scale and multiple-choice questions. Questions addressed three areas: (1) general views toward personal genotyping, (2) views toward personal genotyping as part of a class process, and (3) knowledge questions about interpreting personal genome results. The majority of these closed-ended questions were answered on a five-point Likert scale (e.g., strongly disagree, disagree, neutral, agree, and strongly agree) or with multiple-choice answers that included the option of "I have no idea how to answer this question." Approximately one-third of the questionnaire (18 questions) was devoted to questions from McGuire et al. Another third (16 questions) was made up of questions specific to the use of genotyping in the context of a course. The final section included three clinical scenarios that asked three questions each, about interpretation of genotype data, impact of various clinical factors presented in the scenario on understanding of the case, and how the patient should be counseled.

The survey was distributed through SurveyMonkey.com, an online site for survey administration and data collection. Each precourse and postcourse survey remained open for responses for approximately 1 week. After the initial email containing the survey link, one reminder was sent to students the day before the close of each survey. Each survey took approximately 45 minutes to complete.

The Stanford University Institutional Review Board approved this research, and informed consent was obtained from all participants. No compensation was provided for participation; however, students were informed that the faculty at the School of Medicine was debating whether to proceed with an offer of genotyping to students as part of learning experience, and that their input on these surveys would be taken under consideration as part of the discussion.

\section{Data analysis}

SPSS 17.0 was used to analyze data. To ensure the anonymity of respondents, responses were not paired. Therefore, precourse and postcourse paired data analysis was not possible. Instead, descriptive statistics were analyzed for each of the precourse and the postcourse summary results separately. Data were then compared between the two surveys using Fisher exact tests to discern changes in beliefs, attitudes, and knowledge about genotyping information and DTC genetic testing services. We present statistical significance at the $P=0.10$ level due to the small sample size in this study.

\section{RESULTS}

\section{General views about PGT services}

Table 1 describes the basic views about PGT services. Before the course, $63 \%$ of respondents felt that genome-wide association studies information about common complex traits would be useful for physicians. After the course, however, respondents were less likely to view the information as having utility for the physicians (32\%; $P=0.009$ ), patients ( $47 \%$ precourse to $23 \%$ postcourse; $P=0.094, \mathrm{NS})$, or consumers in general (84\% precourse to $52 \%$ postcourse). However, after the course, students were less likely to view personal genome test results as diagnostic of a medical condition or disease ( $31 \%$ precourse to $16 \%$ postcourse).

Most respondents believed that they themselves understood the risks and benefits of using personal genome services $(61 \%$ precourse and $73 \%$ postcourse). However, no respondents pre- 
Table 1 General views about personal genome testing services

Question
Recent GWAS have successfully identified a number
of genes that contribute to common complex traits,
such as type II diabetes, schizophrenia, heart
disease, and height. Direct-to-consumer genomic
testing will make it possible for patients to learn
their genotype for these traits and to share the
information with their physicians. How useful do
you think this information will be to a physician?

How useful will this information be to patients themselves?

How likely is it that knowing this information for yourself would lead to any changes in your behavior?

In addition to medical and physical traits, GWAS studies have produced a number of well-validated associations with complex behavioral traits (such as risk taking). How useful do you think this information would be to you?

How likely is it that knowing this information about behavioral traits would lead to any changes in your behavior?

Personal genomic testing services are useful for consumers.

I consider information from personal genome testing to be diagnostic of medical conditions or diseases.

If I underwent personal genome testing, I would ask a physician for help in interpreting the results.

Results of personal genome testing would influence my future health care decisions.

I would permit a personal genome testing company to include my de-identified sample for prospective research.

Physicians have a professional responsibility to help individuals understand the results they receive from personal genome tests, even if the physician has not ordered the test.

Physicians have enough knowledge to help individuals interpret results of personal genome tests.

Most people can accurately interpret their personal genome test results.

Personal genome companies tell their customers everything they need to know to make informed decisions about using their services.

I know enough about genetics to understand the personal genome test results.

I understand the risks and benefits of using personal genome services.

Personal genome companies should have a medical expert to help customers interpret their results.

Personal genome companies should be regulated by the federal government.

\begin{tabular}{|c|c|c|c|c|}
\hline \multicolumn{2}{|c|}{ Precourse survey } & \multicolumn{2}{|c|}{ Postcourse survey } & \multirow[b]{2}{*}{$P$} \\
\hline Percentage & $N$ & Percentage & $N$ & \\
\hline $\begin{array}{l}63 \% \text { very useful or } \\
\text { indispensible }\end{array}$ & $27 / 43$ & $\begin{array}{l}32 \% \text { very useful or } \\
\text { indispensible }\end{array}$ & $10 / 31$ & $P=0.009$ \\
\hline
\end{tabular}

$47 \%$ very useful or indispensible

$53 \%$ very likely or almost certain

$21 \%$ very useful or indispensible $24 \%$ very likely or almost
certain

$10 / 42$

$84 \%$ yes

$31 \%$ yes

$79 \%$ yes

$71 \%$ agree/strongly agree

$74 \%$ agree/strongly agree

$87 \%$ agree/strongly agree

$33 / 38$

$32 / 38$

$12 / 39$

$30 / 38$

$27 / 38$

$28 / 38$
$29 \%$ agree $(0 \%$ strongly agree)
$0 \%$ agree/strongly agree
$3 \%$ strongly agree $(0 \%$ agree)

$34 \%$ agree/strongly agree

$61 \%$ agree/strongly agree

$71 \%$ agree/strongly agree

$45 \%$ agree/strongly agree

0

$23 / 38$

$27 / 38$

$17 / 38$
$(0 \%$

indispensible)

$19 \%$ very likely

( $0 \%$ almost

certain)

$52 \%$ yes

$16 / 31$

$20 / 30$

$67 \%$ agree $(0 \%$ strongly agree)

$77 \%$ agree/strongly agree

$70 \%$ agree/strongly agree

$11 / 38 \quad 7 \%$ agree $(0 \%$ strongly agree)

$0 \%$ agree/strongly agree

$3 \%$ strongly agree ( $0 \%$ agree)

$20 \%$ agree/strongly agree

$73 \%$ agree/strongly agree

$80 \%$ agree/strongly agree
$43 \%$ agree/strongly agree
2/30 $P=0.005$

0

NS

$1 / 30$

NS

NS

NS

NS

NS

$P$ values indicate significant values between precourse and postcourse surveys using Fisher exact testing. 
Table 2 Reasons for using (or not using) a personal genome service for self and perceptions about why such services would be useful (or not) for a consumer

\begin{tabular}{|c|c|c|c|c|c|c|c|c|c|c|}
\hline & \multicolumn{2}{|c|}{$\begin{array}{l}\text { Self-precourse } \\
\text { survey }\end{array}$} & \multicolumn{2}{|c|}{$\begin{array}{l}\text { Self—postcourse } \\
\text { survey }\end{array}$} & \multirow[b]{2}{*}{$P$} & \multicolumn{2}{|c|}{$\begin{array}{c}\text { Consumer-precourse } \\
\text { survey }\end{array}$} & \multicolumn{2}{|c|}{$\begin{array}{l}\text { Consumer-postcourse } \\
\text { survey }\end{array}$} & \multirow[b]{2}{*}{$P$} \\
\hline & Percentage & $N$ & Percentage & $N$ & & Percentage & $N$ & Percentage & $N$ & \\
\hline $\begin{array}{l}\text { Would you use a personal } \\
\text { genomics testing service for } \\
\text { yourself now? }\end{array}$ & $57 \%$ yes & $24 / 42$ & $55 \%$ yes & $17 / 31$ & NS & - & - & - & - & \\
\hline $\begin{array}{l}\text { I think personal genomics testing } \\
\text { services are useful for } \\
\text { consumers }\end{array}$ & - & - & - & - & & $84 \%$ yes & $32 / 38$ & $52 \%$ yes & $16 / 31$ & $P=0.004$ \\
\hline \multicolumn{11}{|l|}{$\begin{array}{l}\text { If yes (respondents asked to } \\
\text { check all that apply) }\end{array}$} \\
\hline Satisfy general curiosity & $96 \%$ & $24 / 25$ & $94 \%$ & $16 / 17$ & NS & $77 \%$ & $6 / 34$ & $75 \%$ & $12 / 16$ & NS \\
\hline $\begin{array}{l}\text { See if a specific disease runs } \\
\text { in the family or is in DNA }\end{array}$ & $84 \%$ & $21 / 25$ & $71 \%$ & $12 / 17$ & NS & $100 \%$ & $34 / 34$ & $94 \%$ & $15 / 16$ & NS \\
\hline $\begin{array}{l}\text { Learn about genetic makeup } \\
\text { without going through a } \\
\text { physician }\end{array}$ & $24 \%$ & $6 / 25$ & $24 \%$ & $4 / 17$ & NS & $27 \%$ & $9 / 34$ & $31 \%$ & $5 / 16$ & NS \\
\hline $\begin{array}{l}\text { Inform family members about } \\
\text { health risks }\end{array}$ & $44 \%$ & $11 / 25$ & $18 \%$ & $3 / 17$ & $P=0.072$ & $80 \%$ & $27 / 34$ & $56 \%$ & $9 / 16$ & $P=0.088$ \\
\hline $\begin{array}{l}\text { Understand what a patient } \\
\text { may learn/experience }\end{array}$ & $64 \%$ & $16 / 25$ & $71 \%$ & $12 / 17$ & NS & - & - & - & - & \\
\hline $\begin{array}{l}\text { Help understand principles of } \\
\text { human genetics }\end{array}$ & $40 \%$ & $10 / 25$ & $29 \%$ & $5 / 17$ & NS & - & - & - & - & \\
\hline $\begin{array}{l}\text { Right to know about genetic } \\
\text { makeup if a service is } \\
\text { available }\end{array}$ & - & - & - & - & & $59 \%$ & $20 / 34$ & $56 \%$ & $9 / 16$ & NS \\
\hline \multicolumn{11}{|l|}{$\begin{array}{c}\text { If no (respondents asked to } \\
\text { check all that apply) }\end{array}$} \\
\hline Results are not reliable & $16 \%$ & $3 / 19$ & $50 \%$ & $7 / 14$ & $P=0.042$ & & & & & \\
\hline Results are not accurate & - & - & - & - & & $33 \%$ & $2 / 6$ & $41 \%$ & $7 / 17$ & NS \\
\hline Results are not predictive & - & - & - & - & & $83 \%$ & $5 / 6$ & $47 \%$ & $8 / 17$ & NS \\
\hline $\begin{array}{l}\text { Concern about privacy/risks to } \\
\text { privacy }\end{array}$ & $58 \%$ & $11 / 19$ & $57 \%$ & $8 / 14$ & NS & $50 \%$ & $3 / 6$ & $41 \%$ & $7 / 17$ & NS \\
\hline $\begin{array}{l}\text { Information will not be } \\
\text { medically useful/will not } \\
\text { change medical decisions }\end{array}$ & $11 \%$ & $2 / 19$ & $43 \%$ & $6 / 14$ & $P=0.042$ & $33 \%$ & $2 / 6$ & $12 \%$ & $2 / 17$ & NS \\
\hline $\begin{array}{l}\text { Information will not help learn } \\
\text { human genetics }\end{array}$ & $11 \%$ & $2 / 19$ & $43 \%$ & $6 / 14$ & $P=0.042$ & - & - & - & - & \\
\hline Unwanted information & $52 \%$ & $11 / 19$ & $43 \%$ & $6 / 14$ & NS & $50 \%$ & $3 / 6$ & $41 \%$ & $7 / 17$ & NS \\
\hline Costs too much & $42 \%$ & $8 / 19$ & $43 \%$ & $6 / 14$ & NS & $33 \%$ & $2 / 6$ & $24 \%$ & $4 / 17$ & NS \\
\hline
\end{tabular}

course or postcourse felt that most of the general public could accurately interpret the results, and very few $(3 \%$ before and after the course) believed that personal genomics companies provide clients with everything they need to know to make informed decisions about using their services.

\section{Professional responsibilities in and regulation of personal genomic testing}

Before course instruction, $87 \%$ of respondents agreed or strongly agreed that physicians have a responsibility to help patients interpret the results of personal genome tests, compared with $70 \%$ after the course (Table 1). Similarly, the majority of respondents ( $71 \%$ precourse and $80 \%$ postcourse) felt that companies should provide a medical expert to help clients interpret results. However, few respondents agreed or strongly agreed (29\% precourse and $7 \%$ postcourse; $P=0.005$ ) that physicians actually have enough knowledge to aid in interpretation of test results.

In terms of overarching guidelines for PGT services, most respondents were neutral about (32\% precourse and $43 \%$ post- 
Table 3 If personal genome testing services were offered at a nominal fee as an optional part of this class so that I could analyze my results anonymously in relationship to what I was learning with principles discussed generally in class

\begin{tabular}{|c|c|c|c|c|c|}
\hline \multirow[b]{2}{*}{ Question } & \multicolumn{2}{|c|}{$\begin{array}{l}\text { Precourse survey } \% \\
\text { agree/strongly agree }\end{array}$} & \multicolumn{2}{|c|}{$\begin{array}{l}\text { Postcourse survey } \% \\
\text { agree/strongly agree }\end{array}$} & \multirow[b]{2}{*}{$P$} \\
\hline & Percentage & $N$ (of 39) & Percentage & $N($ of 31$)$ & \\
\hline $\begin{array}{l}\text { My own results would help me understand genetics } \\
\text { concepts better than someone else's results. }\end{array}$ & $67 \%$ & 26 & $45 \%$ & 14 & $P=0.056$ \\
\hline $\begin{array}{l}\text { I would feel that I would be at a disadvantage to } \\
\text { my classmates if I did not undergo the testing. }\end{array}$ & $28 \%$ & 11 & $23 \%$ & 7 & NS \\
\hline $\begin{array}{l}\text { I would see this as an opportunity to get a service } \\
\text { that I would not ordinarily get if I had to pay full } \\
\text { price. }\end{array}$ & $85 \%$ & 33 & $77 \%$ & 24 & NS \\
\hline $\begin{array}{l}\text { I would be concerned that my professors would } \\
\text { know who took up the offer of testing and who } \\
\text { did not. }\end{array}$ & $13 \%$ & 5 & $13 \%$ & 4 & NS \\
\hline $\begin{array}{l}\text { I would be concerned that my classmates would } \\
\text { know who took up the offer of testing and who } \\
\text { did not. }\end{array}$ & $15 \%$ & 6 & $10 \%$ & 3 & NS \\
\hline $\begin{array}{l}\text { I would see this as an opportunity to get } \\
\text { information that would help me improve my } \\
\text { health. }\end{array}$ & $77 \%$ & 30 & $55 \%$ & 17 & $P=0.088$ \\
\hline $\begin{array}{l}\text { I would be concerned that I might get some results } \\
\text { that would be disturbing. }\end{array}$ & $54 \%$ & 21 & $55 \%$ & 17 & NS \\
\hline $\begin{array}{l}\text { I would only take up the offer of testing if I could } \\
\text { get genetic counseling before I sent my sample in. }\end{array}$ & $\begin{array}{l}23 \% \text { agree }(0 \% \\
\text { strongly agree })\end{array}$ & 9 & $23 \%$ & 7 & NS \\
\hline $\begin{array}{l}\text { I would only take up the offer of testing if I could } \\
\text { get genetic counseling after I got my results } \\
\text { back. }\end{array}$ & $41 \%$ & 16 & $52 \%$ & 16 & NS \\
\hline $\begin{array}{l}\text { I would be concerned that people would find out } \\
\text { genetic or health information about me. }\end{array}$ & $51 \%$ & 20 & $52 \%$ & 16 & NS \\
\hline
\end{tabular}

${ }^{a}$ Chi-square analysis values at $P<0.10$ are provided due to small sample size. Other questions did not demonstrate significant differences between the precourse and postcourse survey responses.

course) or in agreement (45\% precourse and $43 \%$ postcourse) with the idea that the federal government should regulate PGT companies.

\section{Interest in undergoing PGT services}

We found that $57 \%$ of respondents were interested in undergoing PGT services before the genetics course, and 55\% were interested after the course, which was not a significant difference. The modal response for what students would be willing to pay for this service was $\$ 25$; more than $75 \%$ selected price options at $\$ 100$ or less, and 16-20\% stated "none." Respondents were slightly more willing to pay for services on the second survey.

Reasons for desiring to undergo PGT services are listed in Table 2. General curiosity was overwhelmingly the most frequently chosen reason for being interested in undergoing PGT both before $(96 \%)$ and after the course $(94 \%)$. Although respondents were less interested in PGT services for learning whether a disease ran in the family after taking the course (84\% precourse and $71 \%$ postcourse), they were more interested in understanding the patients' experiences with PGT services (64\% precourse and $71 \%$ postcourse) and less interested in the idea that they would inform their own family members about health risks (44\% precourse and $18 \%$ postcourse; $P=0.072, \mathrm{NS}$ ).
Of those students who were not interested in undergoing PGT services, the most frequently indicated reasons for not being interested were concerns about privacy (58\% precourse and $57 \%$ postcourse) or receiving unwanted information $(52 \%$ precourse and $43 \%$ postcourse). There were statistically significant increases in those who were not interested in undergoing genotyping because it was seen as unreliable $(P=0.042)$, it would not be medically useful $(P=0.042)$, and it would not help learn human genetics $(P=0.042)$.

Of note, there was a statistically significant decrease in students who felt that "personal genomic testing is useful for consumers" ( $84 \%$ precourse to $54 \%$ postcourse; $P=0.004$ ), and students were also less likely to feel that the information was useful with regard to informing other family members about health risks $(80 \%$ precourse to $56 \%$ postcourse; $P=$ 0.088 , NS).

\section{PGT services in the context of a course}

Table 3 reviews the respondents' views toward the offer of PGT services in parallel with a human genetics course. A majority of respondents ( $85 \%$ precourse and $77 \%$ postcourse) felt that it was an opportunity to get a service that they would not otherwise get if they had to pay full price. After the course, fewer students felt that their own genetic testing results would 
Table 4 Responses to clinical scenario $1^{a}$

\begin{tabular}{|c|c|c|c|c|c|}
\hline \multirow[b]{2}{*}{ Question } & \multicolumn{2}{|c|}{ Precourse survey } & \multicolumn{2}{|c|}{ Postcourse survey } & \multirow[b]{2}{*}{$P$} \\
\hline & Percentage & $N$ & Percentage & $N$ & \\
\hline Interpretation of results (increase in those answering correctly) & & & & & $P<0.001$ \\
\hline Patient is affected with breast cancer & 0 & 0 & 0 & 0 & NS \\
\hline Patient has higher risk than average & 17 & $6 / 35$ & 46 & $12 / 26$ & NS \\
\hline Patient has lower risk than average & 31 & $11 / 35$ & 15 & $4 / 26$ & NS \\
\hline Patient is a carrier of breast cancer and may develop it & 11 & $4 / 35$ & 0 & 0 & NS \\
\hline Patient is a carrier of breast cancer but is unlikely to develop it & 6 & $2 / 35$ & 0 & 0 & NS \\
\hline Patient has no risk for breast cancer & 0 & 0 & 0 & 0 & NS \\
\hline A different genetic test should be ordered & 3 & $1 / 35$ & 27 & $7 / 26$ & NS \\
\hline A different clinical test should be ordered & 0 & 0 & 4 & $1 / 26$ & NS \\
\hline I have no idea what the results mean & 31 & $11 / 35$ & 8 & $2 / 26$ & NS \\
\hline \multicolumn{6}{|l|}{ What issues impacted your understanding of the case? } \\
\hline Family history & 47 & $16 / 34$ & 69 & $18 / 26$ & $(P=\mathbf{0 . 0 7})$ \\
\hline Study sizes & 12 & $4 / 34$ & 4 & $1 / 26$ & NS \\
\hline Samples from the studies & 12 & $4 / 34$ & 8 & $2 / 26$ & NS \\
\hline Odds ratios from the studies & 27 & $9 / 34$ & 15 & $4 / 26$ & NS \\
\hline Penetrance of the condition & 27 & $9 / 34$ & 23 & $6 / 26$ & NS \\
\hline Test results and interpretation by the company & 35 & $12 / 34$ & 19 & $5 / 26$ & NS \\
\hline None of the above & 9 & $3 / 34$ & 8 & $2 / 26$ & NS \\
\hline \multicolumn{6}{|l|}{ How would you counsel the patient? } \\
\hline Should have clinical screening for breast cancer & 42 & $15 / 36$ & 73 & $19 / 26$ & NS \\
\hline $\begin{array}{l}\text { Not at increased risk but should let family know they are a carrier } \\
\text { and others may be at risk }\end{array}$ & 14 & $5 / 36$ & 12 & $3 / 26$ & NS \\
\hline Not at increased risk and no additional intervention needed & 11 & $4 / 36$ & 4 & $1 / 26$ & NS \\
\hline I have no idea how to counsel the patient & 33 & $12 / 36$ & 12 & $3 / 26$ & NS \\
\hline
\end{tabular}

Best answers in bold.

${ }^{a}$ You have a 37-year-old patient who has a family history of breast and ovarian cancer (her mother with bilateral breast cancer at the age of 45 years, her maternal aunt with ovarian cancer at the age of 52 years, and her maternal grandmother with bilateral breast cancer at the age of 50 years). Because she did not want her insurance company to discriminate against her, she underwent testing through a DTC genetic testing company. She wants you to help her understand her testing results so that she can undergo any appropriate screening and/or prophylactic surgeries.

As epidemiologic background, $13 \%$ of the population develops breast cancer in their lifetime, and $5-10 \%$ of cases of breast cancer are estimated to be due to a genetic predisposition. The three studies that addressed the SNPs listed below were published in 2007 . They are all case-control studies that include between $1,600-18,290$ cases and 4,316-22,670 controls. The odds ratios ranged between 0.74 and 1.16 , depending on the SNP and the study.

Your patient's results are as follows, and the company interprets this combination of results as a 9\% lifetime risk: TNRC9, - +; FGFR2, ++; Chr2.217614077, -+ ; CASP8 --; MAP3K1, +-; Chr8.128424800, ++; and LSP1, ++. Presume that + represents the low-risk allele and - represents the at-risk allele.

help them understand genetic concepts better than someone else's results (67\% precourse and $45 \%$ postcourse; $P=0.056$ ) or that it would provide information that would help improve their own health (77\% precourse to $55 \%$ postcourse; $P=0.088$, NS). Approximately half of the respondents both precourse and postcourse had some concern that others would find out genetic or health information about them, but fewer participants were concerned that professors or classmates would find out who took up the testing offer ( $13 \%$ both precourse and postcourse) or that they would be at a disadvantage compared with classmates ( $28 \%$ precourse and $23 \%$ postcourse). Respondents felt more strongly about the availability of genetic counseling after receiving results ( $41 \%$ precourse and $52 \%$ postcourse) than before undergoing testing ( $23 \%$ both precourse and postcourse), and more than half of them, both precourse and postcourse, acknowledged that they may receive results that were disturbing.

\section{Responses to clinical scenarios}

Tables 4 to 6 show the responses to clinical scenarios asking students to interpret genotype results modified from those currently available via DTC personal genetic testing. (Each of these three scenarios is fictional, but based on information an individual may currently obtain from a DTC genetic testing company for complex adult conditions.) A minority initially selected the correct interpretation in any of the three cases, although this percentage did increase in all scenarios after the human genetics 
Table 5 Responses to clinical scenario $2^{a}$

\begin{tabular}{|c|c|c|c|c|c|}
\hline \multirow[b]{2}{*}{ Question } & \multicolumn{2}{|c|}{ Precourse survey } & \multicolumn{2}{|c|}{ Postcourse survey } & \multirow[b]{2}{*}{$P$} \\
\hline & Percentage & $N$ & Percentage & $N$ & \\
\hline \multicolumn{6}{|l|}{ Interpretation of results } \\
\hline Patient is affected with hemochromatosis & 0 & 0 & 0 & 0 & NS \\
\hline Patient has high risk for hemochromatosis & 0 & 0 & 0 & 0 & NS \\
\hline Patient has low risk for hemochromatosis & 18 & $6 / 34$ & 0 & 0 & NS \\
\hline Patient is a carrier and may develop it & 9 & $3 / 34$ & 12 & $3 / 26$ & NS \\
\hline Patient is a carrier but is unlikely to develop it & 24 & $8 / 34$ & 42 & $11 / 26$ & NS \\
\hline Patient has no risk for hemochromatosis & 6 & $2 / 34$ & 8 & $2 / 26$ & NS \\
\hline A different genetic test should be ordered & 0 & 0 & 0 & 0 & NS \\
\hline A different clinical test should be ordered & 0 & 0 & 4 & $1 / 26$ & NS \\
\hline I have no idea what the results mean & 44 & $15 / 34$ & 35 & $9 / 26$ & NS \\
\hline \multicolumn{6}{|l|}{ What issues impacted your understanding of the case? } \\
\hline Mode of inheritance & 58 & $19 / 33$ & 62 & $16 / 26$ & NS \\
\hline Penetrance of the condition & 27 & $9 / 33$ & 50 & $13 / 26$ & $(P=\mathbf{0 . 0 6 4})$ \\
\hline Test results and interpretation by the company & 30 & $10 / 33$ & 35 & $9 / 26$ & NS \\
\hline None of the above & 33 & $11 / 33$ & 19 & $5 / 26$ & NS \\
\hline \multicolumn{6}{|l|}{ How would you counsel the patient? } \\
\hline Should have clinical screening for hemochromatosis & 9 & $3 / 34$ & 27 & $7 / 26$ & NS \\
\hline $\begin{array}{l}\text { Not at increased risk but should let family know they are } \\
\text { a carrier and others may be at risk }\end{array}$ & 21 & $7 / 34$ & 42 & $11 / 26$ & NS \\
\hline Not at increased risk and no additional intervention needed & 21 & $7 / 34$ & 8 & $2 / 26$ & NS \\
\hline I have no idea how to counsel the patient & 50 & $17 / 34$ & 23 & $6 / 26$ & NS \\
\hline
\end{tabular}

Best answers in bold.

${ }^{a}$ Your patient comes to see you with the results from their genomic testing through a DTC genetic testing company. You see that they have undergone genetic testing for hemochromatosis. Through your research on websites like OMIM you learn that hemochromatosis is a condition that is inherited in an autosomal recessive manner with decreased penetrance (estimates vary from 1 to $10 \%$ depending on the specific mutation). You also learn that the treatments for hemochromatosis are regular phlebotomy to reduce the chance for clinical complications due to iron overload.

The results are as follows: HFE-C282Y, ++ ; HFE-H63D, +- ; and HFE-S65C, ++ . Presume that + represents the low-risk allele and - represents the at-risk allele.

course (Scenario 1: $P<0.001$ ). Of note, approximately onethird of all respondents selected "I have no idea what these results mean" even on the postcourse survey, and they were easily distracted by information that was not directly relevant to the case interpretation.

\section{DISCUSSION}

Overall, our results suggest that courses on human genetics that specifically teach concepts about genotyping can be effective at educating students about the limitations of DTC genomics and can change beliefs about the utility of such test results, even without providing genotyping results to individuals. Indeed, students were more skeptical about the educational value of actually getting genotyped after taking the course. However, the course did not seem to change interest in actually receiving genotyping results significantly, perhaps because interest seemed largely motivated by a general sense of curiosity rather than obtaining specific information believed to be clinically useful.

\section{General knowledge and attitudes about PGT services}

Overall, before taking the course, students responded similarly, in many ways, to the respondents of the survey of Facebook users reported by McGuire et al. ${ }^{15}$ The demographics of both groups were quite similar although our sample was slightly younger on average ( $<30$ years vs. 35 years) and virtually all had at least a bachelor's degree (or were in the process of completing a premedical curriculum) when compared with McGuire's sample of Facebook users (39\%). There was similar interest in using personal genomics between the two groups (57\% in our precourse sample vs. $64 \%$ in the sample of Facebook users) and similar reasons for using PGT services: general curiosity ( $96 \%$ in our sample vs. $81 \%$ of the Facebook users), to determine if a disease ran in the family ( $84 \%$ in our sample vs. $75 \%$ in McGuire's study). However, there were similar proportions of the two samples of those concerned about cost of PGT services (42\% in our sample vs. $40 \%$ in McGuire's sample).

However, respondents to McGuire's survey who were not interested in PGT services were less concerned than our student sample about the reliability of the results $(21 \%)$, privacy $(39 \%)$, 
Table 6 Responses to clinical scenario $3^{a}$

\begin{tabular}{|c|c|c|c|c|}
\hline \multirow[b]{2}{*}{ Question } & \multicolumn{2}{|c|}{ Precourse survey } & \multicolumn{2}{|c|}{ Postcourse survey } \\
\hline & Percentage & $N$ & Percentage & $N$ \\
\hline \multicolumn{5}{|l|}{ Interpretation of results } \\
\hline Patient is affected with macular degeneration & 3 & $1 / 34$ & 0 & 0 \\
\hline Patient has higher risk than average & 44 & $15 / 34$ & 56 & $14 / 25$ \\
\hline Patient has lower risk than average & 0 & 0 & 0 & 0 \\
\hline Patient is a carrier and may develop it & 6 & $2 / 34$ & 8 & $2 / 25$ \\
\hline Patient is a carrier but is unlikely to develop it & 3 & $1 / 34$ & 0 & 0 \\
\hline Patient has no risk for macular degeneration & 0 & 0 & 0 & 0 \\
\hline A different genetic test should be offered & 0 & 0 & 0 & 0 \\
\hline A different clinical test should be offered & 0 & 0 & 0 & 0 \\
\hline I have no idea what the results mean & 44 & $15 / 34$ & 36 & $9 / 25$ \\
\hline \multicolumn{5}{|l|}{ What issues impacted your understanding of the case (check all that apply)? } \\
\hline Family history & 22 & $7 / 32$ & 36 & $9 / 25$ \\
\hline Study sizes & 6 & $2 / 32$ & 4 & $1 / 25$ \\
\hline Samples from the studies & 9 & $3 / 32$ & 0 & 0 \\
\hline Odds ratios from the studies & 16 & $5 / 32$ & 0 & $0(P=0.048)$ \\
\hline Penetrance of the condition & 28 & $9 / 32$ & 24 & $6 / 25$ \\
\hline Test results and interpretation by the company & 44 & $14 / 32$ & 56 & $14 / 25$ \\
\hline None of the above & 35 & $11 / 32$ & 28 & $7 / 25$ \\
\hline \multicolumn{5}{|l|}{ How would you counsel the patient? } \\
\hline Should have clinical screening for macular degeneration & 59 & $20 / 34$ & 64 & $16 / 25$ \\
\hline $\begin{array}{l}\text { Not at increased risk but should let family know they are a carrier and } \\
\text { others may be at risk }\end{array}$ & 0 & 0 & 4 & $1 / 25$ \\
\hline Not at increased risk and no additional intervention needed & 0 & 0 & 4 & $1 / 25$ \\
\hline I have no idea how to counsel the patient & 41 & $14 / 34$ & 28 & $7 / 25$ \\
\hline
\end{tabular}

Best answers in bold.

${ }^{a}$ Your patient has a grandparent with macular degeneration. He is concerned about the chance he may develop it.

About 3\% of the population develops macular degeneration, and you learn that about $66 \%$ of the risk for macular degeneration is due to a genetic predisposition. You also learn that one of the studies that influenced available genetic testing included 4757 phenotyped subjects, but that not all of them had genetic testing results. You review their genetic testing results and find the following: LOC387715-S69A, -+; CFH-intron, --; CFB, --; C2-E318D, --; CFH-Y402H, -+; and C3-R80G, --.

Presume that + represents the low-risk allele and - represents the at-risk allele.

utility of returned information $(53 \%)$, or receipt of unwanted information $(21 \%)$. This difference might reflect a greater familiarity with genetics or biology among our student sample.

Our sample, largely composed of future physicians, was much less confident of their own knowledge about genetics or the ability of their future patients to understand results of PGT services than respondents in McGuire's survey, even before taking the course. Nevertheless, the majority of students still believed that physicians have a professional responsibility to help patients interpret the results of PGT services, although fewer agreed that they had such responsibility after the course. This change may reflect an appreciation for the complexity of the information and realization of how this may impact the future role of physicians.

Our sample was far more skeptical than McGuire's respondents that customers are adequately informed by personal genome companies, but most felt that these companies should provide customers with access to medical experts. The greater concerns about PGT services in our sample, including worries about reliability and utility of results, might have led to greater awareness of potential shortcomings of information provided by personal genome companies and greater desire for involvement of medical experts.

\section{Impact of a human genetics course}

Completing a graduate level human genetics course clearly had a significant effect on students' views and understanding of PGT services. Students spent a considerable number of course hours covering SNP analysis and genotyping, which might have increased understanding of the clinical and other limitations of PGT services. After the course, students were much less likely to agree that genotyping information of the type that is commercially available would be useful to patients, consumers, or physicians, and they were much less likely to feel that PGT 
services provide reliable information. Nevertheless, even after many hours of course work, students still had difficulty interpreting genotyping data in the context of clinical scenarios. In two of three scenarios, less than half of the respondents gave the answer(s) reflecting the best clinical interpretation(s) of the genotyping results, even after taking the course. This difficulty highlights the complexity of understanding the clinical implications of genotypes and suggests that additional and/or different types of education are needed for adequate understanding of application of genotyping data to a clinical context.

However, despite an increased understanding of the limitations of PGT services, student interest in undergoing genotyping did not significantly change. These results suggest that education about human genetics significantly changes beliefs about PGT services among a group of educated potential consumers and clinicians-in-training, but that these changes do not alter reported interest in being genotyped.

\section{Limitations}

The generalizability of our study is limited by the relatively small sample size and lack of direct before-after comparison to enhance anonymity. In addition, we do not know the extent to which the presence of nonmedical students may have biased the results (particularly because those students did not take the Molecular Medicine course), and we are not able to assess how many nonmedical students completed each survey. Finally, because this survey measure is not validated, it remains possible that some of our findings are related to unclear wording or confusion in the questions.

\section{Implications for educational institutions}

Our survey results suggest that medical schools and universities that are considering the addition of personal genotyping to their educational programs should consider the issues of student vulnerability, confidentiality, and availability of genetic counseling postresults as part of any processes developed. Furthermore, given the difficulty in accurately responding to clinical scenarios even after completing a medical genetics course supports the difficulty of providing sufficient information to students to facilitate adequate interpretation of genotyping results. Undergraduate students, especially those less familiar with biology, genetics, and medical principles, could be at a greater disadvantage in understanding the benefits and limitations of PGT services.

Given that a large proportion of our students did not feel that genotyping would help in learning about human genetics and that most were interested in genotyping on the basis of "curiosity," the educational benefits of actually providing PGT services should be rigorously evaluated, and studies are needed in programs that do incorporate genotyping to determine what influence, if any, there is on the learning process. Programs should also consider whether having the school subsidize the cost of genotyping the students too strongly encourages students to be genotyped, because of the high cost of PGT services at this time and the inability or unwillingness of students to pay for such services on their own. Finally, educational institutions should consider recently reported investigations of personal genomics companies by the General Accounting Office and hearings by the Food and Drug Administration and Congress have questioned the reliability and clinical validity of such services in deciding whether such services are appropriate to offer in the absence of professional clinical guidance. ${ }^{16}$

\section{ACKNOWLEDGMENTS}

This work was supported, in part, by NIH Grant P50 HG003389 (K.O., J.L., D.M., M.C., and H.G.)

\section{REFERENCES}

1. Hamilton A. The retail DNA test. Time Magazine. October 29, 2008. Available at: http://www.time.com/time/specials/packages/article/0,28804, 1852747_1854493_1854113,00.html. Accessed July 9, 2010.

2. SACGHS. The integration of genetic technologies into health care and public health. SACGHS Progress and Priorities Report to HHS Secretary. 2009:1-44.

3. Burke W, Psaty BM. Personalized medicine in the era of genomics. JAMA 2007;298:1682-1684

4. Hunter DJ, Khoury MJ, Drazen JM. Letting the genome out of the bottlewill we get our wish? N Engl J Med 2008;358:105-107.

5. Magnus D, Cho MK, Cook-Deegan R. Direct-to-consumer tests: beyond medical regulation? Genome Med 2009;1:17.

6. Pollack A. Walgreens delays selling personal genetic test kit. New York Times. May 12, 2010. Available at: http://www.nytimes.com/2010/05/13/ health/13gene.html. Accessed July 9, 2010.

7. Caulfield T. Direct-to-consumer genetics and health policy: a worst-case scenario? Am J Bioeth 2009;9:48-50.

8. McGuire AL, Burke W. An unwelcome side effect of direct-to-consumer personal genome testing: raiding the medical commons. JAMA 2008;300: 2669-71.

9. Federal Trade Commission. At-home genetic tests: a healthy dose of skepticism may be the best prescription. Washington, DC: Bureau of Consumer Protection Division of Consumer and Business Education, 2006.

10. Gollust SE, Wilfond BS, Hull SC. Direct-to-consumer sales of genetic services on the internet. Genet Med 2003;5:332-337.

11. Dougherty MJ. Closing the gap: inverting the genetics curriculum to ensure an informed public. Am J Hum Genet 2009;85:6-12

12. Metcalf MP, Tanner TB, Buchanan A. Effectiveness of an online curriculum for medical students on genetics, genetic testing and counseling. Med Educ Online 2010;15.

13. Wiener CM, Thomas PA, Goodspeed E, Valle D, Nichols DG. "Genes to society"- the logic and process of the new curriculum for the Johns Hopkins University School of Medicine. Acad Med 2010;85:498-506.

14. Fishman J. The age of personal genomics. Paper presented at the 5 th International DNA Sampling Conference. Banff, September 18, 2009

15. McGuire AL, Diaz CM, Wang T, Hilsenbeck SG. Social networkers' attitudes toward direct-to-consumer personal genome testing. Am J Bioeth 2009;9:3-10

16. Kutz G. Direct-to-consumer genetic tests: misleading test results are further complicated by deceptive marketing and other questionable practices. Testimony before the House Subcommittee on Oversight and Investigations, Committee on Energy and Commerce, House of Representatives. Washington, DC: US Government Accountability Office, 2010. 